\title{
Implementing Communicative Activities in English Reading Class
}

\author{
Yonghong Gao \\ School of Foreign Languages, Shandong University of Finance, Jinan 250014, China \\ E-mail: yhgao1048@sina.com
}

\begin{abstract}
This paper aims to analyze and expound the implementing of communicative activities in English Reading classroom. It is mainly untaken from these aspects: 1) polishing teacher's role in communicative activities; 2) Specific communicative activities in classroom; 3) Teacher's questions; 4) Teacher's evaluation. It is believed that communicative activities in classroom is an effective way both for teachers' reading teaching and for students' reading learning if they are properly implemented.
\end{abstract}

Keywords: Communicative activities, English Reading class, Teacher's role, Teacher's questions, Teacher's evaluation

\section{Introduction}

According to the new national Syllabus for English majors, English Reading class is aimed at training students' English reading comprehension and improving their reading speed: training students' ability of meticulous observation of language, and such logic reasoning abilities as assuming, judging, analyzing and summarizing, improving their reading skills, including skimming, scanning and so on, and helping students enlarge vocabulary, absorb language and cultural background knowledge through reading training. It goes without saying that ability training has become a higher priority. Implementing communicative activities is one of the effective ways to train students' abilities and their absorption of knowledge. As a matter of fact, communicative activities in classroom is an effective way both for teachers' reading teaching and for students' reading learning if they are properly implemented.

By a "communicative activity", we mean motivated activities, topics, and themes which involve the students in authentic communication. In communicative activities, students will find themselves in various real-life situations where the target language must be used. Because the focus is not on learning specific language features but on putting the language to use as the circumstances require, students can learn and acquire the language subconsciously, most importantly, students can learn to use their ideas, pass on their ideas and receive ideas, in this way to enlarge their vocabulary, broaden their knowledge, and be more interested to read more and read better.

\section{Categories of communicative activities in classroom}

Usually communicative activities fall into four broad categories: (a) the conduct of the English Reading class; (b) topics arising from and relevant to the students' personal life; (c) substantive topics which are educationally or professionally significant; (d) communicative classroom exercises, i.e. small-scale activities that enable students to practice characteristic features of English discourse, especially "pair work", "group discussion", "role play" are frequently used.

\section{Polishing teacher's role in communicative activities}

\subsection{Making work easy}

As a communicative activity, the focus is not on the use of any particular grammatical form or speech function. The point is to experience the relationship between language use and task fulfillment. Therefore, the delivery ---lecture, readings, explanations, tasks expected of the students---must be adjusted to the students' level of proficiency. If the subject matter is expressed with unfamiliar vocabulary or if the discourse structure is complicated, it may tax the students unduly. So the chief thing for the teacher is to make meaning evident, that is, to ensure that the language input to the student is comprehensible and is in fact comprehended. In Krashen's terminology, success depends on comprehensible input, so teachers have to be conscious of the students' ability to cope with the new subject matter in an imperfectly known language. Here are the ways:

- Explain terminology more carefully

- Use more visuals and diagrams

- Make the delivery slower and more distinct

- Make the tasks assigned to students appropriately scaled down 
Needless to say, exposed to such language conditions, students can, of course, have much confidence, and accordingly have more interests and will more willingly take part in classroom activities.

In fact, the actions and tasks need not be complicated. Especially in the early stages it is quite acceptable, and indeed very satisfying, for students to carry out simple actions and tasks.

\subsection{Creating a pleasant atmosphere}

Communicative activities are likely to be more difficult to engage in under condition of stress, discomfort, fatigue, emotional distress, or hostility than in a calm and positively toned situation. So it is desirable and necessary to create a comfortable and harmonious atmosphere where students are not afraid to speak and enjoy communicating with others. If the atmosphere in the group or in the class is hostile and the student concerned is afraid of being ridiculed or mocked, inhibition will occur. A relaxed and friendly atmosphere is the first essential requirement. It is of great help for the students to pass on their own ideas naturally if the teacher could be more friendly, encouraging a relaxed attitude, and creating a non-threatening environment.

\subsection{Reducing teacher talk}

It is universally accepted that language is a means of communication, and that students learn the target language as a communicative tool, not as a system of linguistic knowledge. So students' talk time is very crucial for the students to master the target language and use it in their daily life. If students want to express themselves deeply and fully, they must have adequate time. If teacher's talk dominates the class, students will consequently have little time to discuss, even some students may have no chance to speak before the class is over. Students should have enough time for discussion if the aim of the task is to be attained. It is realistic for teachers to plan carefully to decrease teacher talk time in a time-limited classroom and turn to student-centered approach.

\subsection{Improving the quality of teacher talk}

In student-centered classroom, teacher should attach more importance to the quality of their talking since their talk time is decreased. According to modern pedagogy, a qualified teacher's language in classroom should be: first, accurate; second, logical; third, standard; fourth, succinct; fifth, rhythmical. This is the basic demand. "Men are intelligent creatures who will feel bored when their intelligent needs can not be met." Said Professor Liu Runqing. So if we want students to show real interest and enthusiasm in participation, what is the most important is "to attract students with the power of knowledge, to excite students with rich content, and to conquer students with the power of wisdom" $(\mathrm{Xu}$ Guozhang) What's more, teachers need to convey a sense of self-confidence in using the language.

\section{Communicative activities in classroom}

\subsection{Group work}

When the detailed work of the text is over (when reading has been completed), global understanding must be returned to and the text as a whole evaluated and responded to. Usually at this stage is communicative activities used.

Most of the work at this stage is best done orally, since discussion and exchange of views are of its essence. Specific tasks can be undertaken in groups before whole class discussion. Why is work done in groups? In group work, individual efforts are pooled and discussed to arrive at the best interpretation of the text. There are important advantages. Motivation is generally high, provided the tasks are challenging and promoting discussion. Students participate more actively, partly because it is less threatening than participating in front of the whole class and partly because it is more obvious that everyone's contribution counts. And the discussion helps students to see how to read thoughtfully.

Moreover, working in groups makes it possible for students to help one another and, in successful groups, the interaction achieves far more than individuals can working on their own. Helping one another is not only emotionally satisfying, it creates the right conditions for learning. Working together can be very motivating and a slight sense of competition between groups does no harm.

To be useful for group work, a task must specify exactly what is to be done, engage every member of the group and promote vigorous discussion. Some textbook questions or activities are suitable for group work, or you may have to supply extra tasks for this purpose. Well-planned questions make students realize they do not understand, and focus attention on the difficult bits of the text.

It is important to have a classroom climate that encourages students to say what they really think. Neither you nor the students must be afraid to be wrong. You must help them to see questions not as attempts to expose their ignorance, but as aids to successful exploration of the text.

Teacher's attitude to wrong answers is crucial. A perfect answer teaches little, but each imperfect answer is an opportunity for learning-not just for the answerer but for the whole class. If it is partly acceptable, teacher can praise the student for what he has understood, and help him (and his classmates) to find clues that will lead to a completely satisfactory interpretation. 
Group discussions are popular 'because the participants were expressing their own ideas rather than performing in a hypothetical situation'. Through discussion, the students can learn the processes of critical thinking that good readers use. Group work is ideal, because in small groups (maximum five members), even the weaker students should be active and learning.

\subsection{Role-play and drama techniques}

Another way of widening the communicative possibilities is by role-play, scenarios, and other drama techniques. The main interest of these techniques lies in the global use of language in lifelike situations and the deep understanding of the reading materials.

In many cases, these techniques approximate real-life language use to a remarkable degree. The use of language in a dramatic situation is likely to include the full complexity of language use: emotional overtones, posture, gesture, and appropriate actions. So, the more closely the student can identify with the role or task the more it provides a natural language experience. Meanwhile, a better understanding of the reading material can be achieved. Understanding is deepened and made clearer when, for example, the student playing the role of $\mathrm{X}$ has to decide-with the help of the others-what $\mathrm{x}$ is doing at any given point, what expression he is likely to have on his face, how he will behave towards $\mathrm{Y}$, why he says this rather than that. Take Unit 8 of Extensive Reading 3, this passage tells us that about 85 percent of the people who smoke wish they could stop, and yet they have to go through the agony of quitting. In order to help students have an authentic experience, I asked 4 students to play the roles of Molly, his friends Bill, Mary and Tim. To give a good impression to the class, and to have an impressive performance, the students read the whole article carefully with great interests. After a short-time preparation, each of them played their role vividly, their performance were met with unanimous applause.

It is important to understand that what we have in mind is not a display in which a few students are actors while the others are an audience. On the contrary, the strength of this approach is that everyone is actively involved in suggesting, discussing interpretations and so on.

\section{Questions}

After group discussion or role-play, the whole class discussion follows in order to have a comprehensive understanding. At this stage, teacher's skill in using the questions is critical.

\subsection{Simplifying}

The language that you ask questions should be simple, clear, easy to understand, including vocabulary that students are familiar with. It's a necessity that the language of questions be simplified in spite of the profound meaning of the questions.

\subsection{Moderating}

Questions you ask should correspond with students' level of knowledge, capability of thinking. The purpose of communicating is to tempt the students to express opinions, to exchange different understanding or ideas, is there any point in inhibiting their expression by questions beyond their knowledge and questions that they cannot control?

\subsection{Asking thought-provoking questions}

The aim of the study is not just to expand knowledge, but also through the analysis and synthesis of information to develop students' cognitive skills training, thinking, and problem-solving abilities. There should not be too many questions related to information, questions that inspire thinking should be asked as many as possible - this is the key to effective teaching.

\subsection{Asking challenging questions}

Simplifying or moderating questions does not mean asking questions which need easy answers, it's useless or meaningless to ask such questions, or it's a waste of time, in other words. The questions should have a certain degree of difficulty where students' language skills, thinking skills, and level of knowledge are concerned, thus they will be of greater challenge. The correct answers to such challenging questions would bring students much self-confidence, and play an important role in the development of students' abilities.

\subsection{Asking follow-up questions}

When students' answers are inadequate, incomplete, teachers should continue to ask questions, through such means as giving hints or suggestion to help students give the right answers. When the questions are correctly answered, teachers should also ask further questions on the basis of their answers, so that the questions become more and more profound to inspire students to discuss. Follow-up questions can avoid the one-time interactive phenomenon, increasing students' participation.

\subsection{Asking questions relevant to students}


If talking about the topics that students understand, and the questions which are related to the experience of the students, students will be more interested, they will have more ideas, they will be more willing to pass on ideas, they will be more open-minded to receive ideas, and subsequently, it will enhance the sense of participation. Especially after the text work, if there are always some questions which are associated with students' life, either outside or inside the campus, it is likely that students will try, more exactly, will be interested to read more to have themselves enriched.

\section{Evaluation}

\subsection{Praising}

Praising is the recognition of the capabilities of the students. Particularly, the poor students need praising more, for their self-confidence can be brought back in this way and they can achieve success accordingly. But students of different ages have different needs for the recognition. Along with the growth of age, students hope that they get more recognition of their peers than the verbal praise from teachers. Remember, it's unnecessary to give praise to the specially simple question. Anyway, praising can enhance students' achievement. With progress feedback a student will be able to successfully self-monitor, have higher aspirations for further achievement, greater self-satisfaction, and higher performance overall.

\subsection{Encouraging}

When students can't answer adequately or when students could not answer questions, teachers should give proper incentives, to provide hints to help analyze the causes. Never use sarcastic comments in order not to dampen the students' self-esteem. Teacher should take a positive attitude toward students' mistakes and take it in mind that errors are natural and inevitable in the process of learning and practicing. Not only that, teachers should encourage students by all manner of means including smile on face, appropriate positive feedback to their work, and so on. Tapping students' resources prove more important than finding faults with them.

\subsection{Quoting}

Quoting is a kind of indirect recognition. In presenting the answer, or making the conclusion, if a teacher can quote the word that students use, better results will be achieved than using oral praise. Such language as "Just as ...said just now, ..." will make the student taste the sense of success, recognition, thus arousing enough of their self-confidence to work quietly at the goal of higher learning.

\subsection{Gesturing}

Besides verbal praising and quoting, gestures and expressions are also helpful in evaluation. Teaching gestures appear in various shapes: hand gestures, facial expressions, body movements, etc. They can either mime or symbolize something and they truly help the students to infer the meaning of the verbal, providing that they are unambiguous and easy to understand. Findings indicate that students generally believe that gestures and other non-verbal behaviors play a key role in communication. There are three types of functions that gestures play in classroom interaction: (1)cognitive, i.e., gestures which work as enhancers of the learning processes, (2)emotional, i.e., gestures that function as reliable communicative devices of teachers' emotions and attitudes and (3)organisational, i.e., gestures which serve as tools of classroom management. These findings suggest that students interpret teachers' gestures in a functional manner and use these and other non-verbal messages and cues in their learning and social interaction with the teacher. Therefore, proper gestures and facial expressions should not be ignored.

\section{Conclusion}

To conclude, classroom management, different topics, field of discourse and various tasks can present students with a rich variety of communicative events to react to. Implementing communicative activities in comfortable reading classroom will provide more opportunities for subconscious assimilation, and open more channels of communication to the target community at a personal level of contact. Not only teachers but also students will benefit a lot from such activities.

\section{References}

Christine, Nuttall. (2002) Teaching Reading Skills In A Foreign Language. Shanghai Foreign Language Education Press.

H, H, Stern. (1996). Issues and Options in Language Teaching. Shanghai Foreign Language Education Press.

Li, Shunying. (1999). On the Effectiveness of Teacher Talk in the ELT Classroom. Teaching English in China. Issue 36. December. 1999. Beijing. Foreign Language Teaching and Research Press.

Liu, Naiyin. (2006). Extensive Reading 3. Higher Education Press.

Song, Meimei. (1999). On Students' Participation in English Classes. Teaching English in China. Issue 36. December. 1999. Beijing. Foreign Language Teaching and Research Press. 
Shen, Suping. (2000). What Do Teachers Bring to the Teaching-learning Progress? Teaching English in China. March. 2000. Beijing. Foreign Language Teaching and Research Press.

Wang, Duqin. (2002). On Strategies of English Teaching. Foreign Language Teaching and Research Press. 